\title{
Long Non-Coding RNAs: Emerging and Versatile Regulators in Host-Virus Interactions
}

\author{
Xing-Yu Meng1, Yuzi Luo', Muhammad Naveed Anwar', Yuan Sun', Yao Gao', \\ Huawei Zhang ${ }^{1}$, Muhammad Munir ${ }^{2}$ and Hua-Ji Qiu ${ }^{1 *}$ \\ 'State Key Laboratory of Veterinary Biotechnology, Harbin Veterinary Research Institute, Chinese Academy of Agricultural \\ Sciences, Harbin, China, ${ }^{2}$ The Pirbright Institute, Woking, United Kingdom
}

Long non-coding RNAs (IncRNAs) are a class of non-protein-coding RNA molecules, which are involved in various biological processes, including chromatin modification, cell differentiation, pre-mRNA transcription and splicing, protein translation, etc. During the last decade, increasing evidence has suggested the involvement of IncRNAs in both immune and antiviral responses as positive or negative regulators. The immunity-associated IncRNAs modulate diverse and multilayered immune checkpoints, including activation or repression of innate immune signaling components, such as interleukin (IL)-8, IL-10, retinoic acid inducible gene I, toll-like receptors 1,3 , and 8, and interferon (IFN) regulatory factor 7 , transcriptional regulation of various IFN-stimulated genes, and initiation of the cell apoptosis pathways. Additionally, some virus-encoded IncRNAs facilitate viral replication through individually or synergistically inhibiting the host antiviral responses or regulating multiple steps of the virus life cycle. Moreover, some viruses are reported to hijack host-encoded IncRNAs to establish persistent infections. Based on these amazing discoveries, IncRNAs are an emerging hotspot in host-virus interactions. In this review, we summarized the current findings of the hostor virus-encoded IncRNAs and the underlying mechanisms, discussed their impacts on immune responses and viral replication, and highlighted their critical roles in host-virus interactions.

Keywords: long non-coding RNAs, viral replication, antiviral response, virus-host interactions, regulatory mechanisms

\section{INTRODUCTION}

With the rapid development of DNA sequencing technologies, the whole genomes of several species have been mapped and annotated. The first transcriptome analysis performed a decade ago came to a surprising conclusion that only about $2 \%$ of the genomic DNA harbors proteincoding genes (1). In the beginning of the 21 st century, Okazaki et al. have analyzed the mouse transcriptome based on a cDNA library and identified a mass of non-coding RNAs (ncRNAs), which are defined as a class of RNA molecules without protein-coding capacity (2). In addition, the Encyclopedia of DNA Elements (ENCODE) project has widely been applied to identify the functional DNA elements in the human genome, and showed that approximately $62 \%$ of the transcriptome is ncRNAs $(3,4)$, indicating ncRNAs as major components of the transcriptome (5). In comparison with mRNAs, less is known about the functions and underlying mechanisms of ncRNAs in different biological processes. Based on the sequence length, ncRNAs are usually 


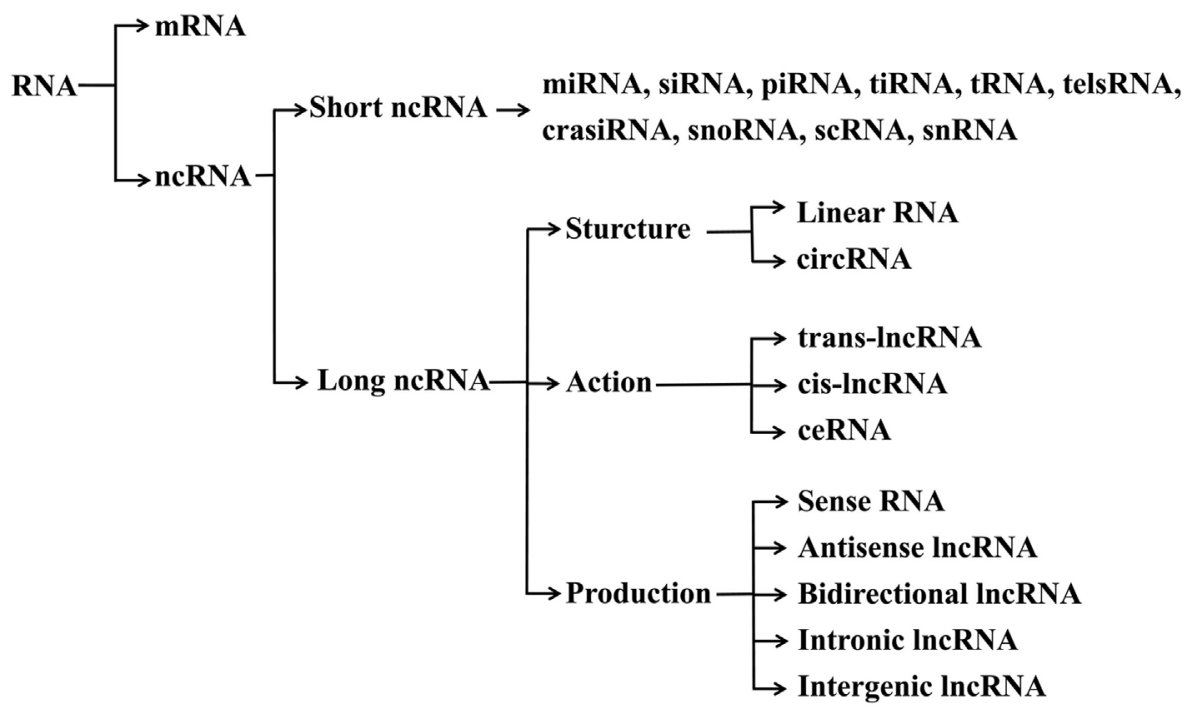

FIGURE 1 | Classification of ncRNAs. mRNA, messenger RNA; ncRNA, non-coding RNA; miRNA, microRNA; siRNA, small interfering RNA; piRNA, piwi RNA; tiRNA, transcription initiation RNA; tRNA, transfer RNA; telsRNA, telomere-specific small RNA; crasiRNA, centromere repeat-associated small interacting RNA; snoRNA, small nucleolar RNA; scRNA, small cytoplasmic RNA; snRNA, small nuclear RNA; trans-IncRNA, trans-acting long non-coding RNA; cis-IncRNA, cis-acting long non-coding RNA; ceRNA, competing endogenous RNA.

divided into long ncRNAs (lncRNAs, more than $200 \mathrm{nt}$ ) and short ncRNAs (sncRNAs, less than $200 \mathrm{nt}$ ) (6) (Figure 1).

In recent years, IncRNAs have been found to be critical regulators in various biological processes such as cell differentiation, chromatin modification, pre-mRNA transcription and splicing, and protein translation and translocation (7-9). Under a natural physiological state, lncRNAs usually function through enhancing or inhibiting the expression of neighboring protein-encoding genes (10). However, the investigation of potential roles of lncRNAs in virus-host interactions is still in the infancy stage. As a wide range of immunity-related lncRNAs has been identified based on differential expression analysis in response to viral infections, the host lncRNAs have been shown to act as regulators in the innate or adaptive immune signaling pathways $(11,12)$. Furthermore, emerging evidence demonstrates that viral genomes can transcribe their own lncRNAs by using the host transcription machinery, and these lncRNAs may be involved in the virus life cycle to regulate host or viral gene expression. Meanwhile, viruses can also regulate the expression of host lncRNAs to establish and maintain persistent infections.

For decades, studies on virus-related host immune responses have been focused mainly on genes or proteins. However, recent studies have shown that lncRNAs may also participate in these biological processes. This review will focus on the lncRNAs involved in host-virus interactions and underlying regulatory mechanisms.

\section{SOURCES AND FUNCTIONS OF IncRNAs}

Most of eukaryotic lncRNAs are transcribed by RNA polymerase II, whereas a limited number of lncRNAs are transcribed by cellular RNA polymerase III (13). After transcription and modification processes, some mature lncRNAs have a similar structure to that of mRNA, including methylguanosine at $5^{\prime}$-terminus and a polyadenylated $[$ poly $(\mathrm{A})]$ tail at the $3^{\prime}$-terminus $(13,14)$. Indeed, broader analysis has suggested that $39 \%$ of $\operatorname{lncRNAs}$ transcripts contain one or more of the six most common poly(A) motifs, compared with $51 \%$ observed for coding transcripts (13). These properties indicate that there are few particular structural features that allow differentiation of lncRNAs from mRNAs. Nevertheless, compared with mRNAs, lncRNAs are more specific in spatial expression and poorly conserved $(15,16)$. To date, five possible sources of lncRNAs have been verified: (1) DNA fragments can be assembled and transformed into a functional lncRNA; (2) due to chromosomal rearrangement, two or more mutually independent sequences link together to generate a lncRNA; (3) due to retrotransposition, duplication of non-coding genes can generate functional or non-functional lncRNAs; (4) duplication events from two neighboring tandems give rise to a sequence repeat lncRNA; (5) insertion of a transposable element in a gene generates a lncRNA (17).

In recent years, lncRNAs have been confirmed as a novel group of regulatory molecules in a wide range of biological or cellular processes (17-21). In the nucleus, IncRNAs participate in regulating the expression of nearby and overlapping genes in either RNA-independent or transcription-initiation manner after epigenetic modification (22). The IncRNA HOTAIR has been proved to repress gene expression by recruiting the histone protein (20). IncRNAs may function as enhancers to promote the expression of nearby genes (23-25). At the promoter regions, lncRNAs overlap with DNA sequence and assist the gene to maintain the transcriptional condition, which may be a common function in cis-regulation (26). In addition, lncRNAs can competitively bind to 


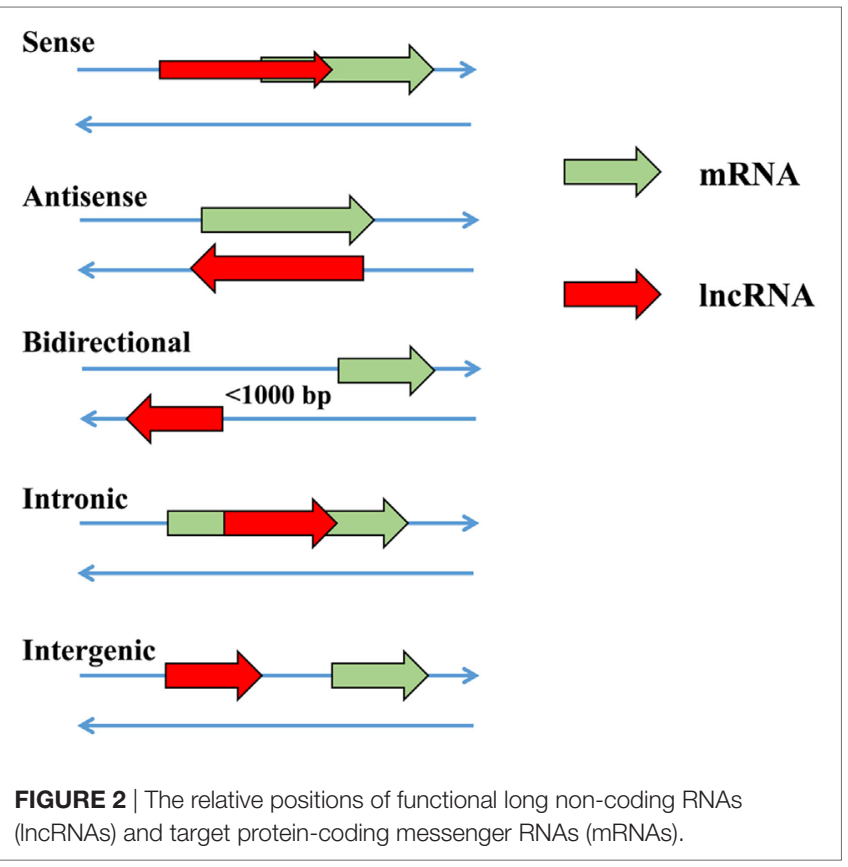

miRNAs to prevent the degradation or repression of target mRNA $(27,28)$. Based on transcriptional directions and relative positions with target mRNAs, lncRNAs are usually classified into five major categories, i.e., sense lncRNAs, antisense lncRNAs, bidirectional lncRNAs, intrinsic lncRNAs and intragenic lncRNAs (29) (Figure 2). The antisense lncRNAs comprise a significant proportion (almost 20\%) of the total lncRNAs in mammalian genomes and $75 \%$ antisense lncRNAs are able to upregulate the expression of adjacent genes (30). In addition, more than $50 \%$ of proteincoding genes carry a complementary lncRNAs in mammals (31).

\section{ANTIVIRAL ACTIVITIES OF HOST IncRNAs}

\section{IncRNAs Are Involved in the Innate Immune Responses against Viral Infections}

As mentioned above, diverse biological processes in eukaryotic cells are regulated by $\operatorname{lncRNAs}$. However, it is noteworthy that viral infections may lead to the differential expression of host lncRNAs and this change seems to exist as a common pathological phenomenon (32-36). Some differentially expressed host lncRNAs may exert antiviral actions involved in different immune signaling pathways. Guttman et al. reported the modulation of lncRNAs transcription by regulatory proteins for the first time and uncovered over 100 lncRNAs with potential functions in four mouse cell types, i.e., mouse embryonic stem cells, mouse embryonic fibroblasts, mouse lung fibroblasts, and neural precursor cells, by using chromatin immunoprecipitation and massive parallel sequencing (37). Furthermore, it has also been confirmed that the transcription of lncRNAs is associated with immunity-related factors, such as nuclear factor $\kappa \mathrm{B}(\mathrm{NF}-\kappa \mathrm{B})$ (39 lncRNAs), sex-determining region of Y chromosome-related high-mobility-group box 2 (Sox2) (20 lncRNAs), and p53 (118
IncRNAs). With the widespread applications of microarray and RNA sequencing technologies, differentially expressed lncRNAs have been identified to be involved in innate immune responses (32, 38-43).

\section{IncRNAs Regulate the Interferon (IFN) Pathway of the Innate Immune Response}

The lncRNA nuclear enriched abundant transcript 1 (NEAT1) is a well-defined positive regulatory component in interleukin (IL)-8 signaling pathway, which can activate the antiviral response. Influenza virus, human immunodeficiency virus (HIV), and other viral infections induce the expression of NEAT1, leading to the formation of nuclear body paraspeckles $(44,45)$. Splicing factor proline/glutamine-rich (SFPQ) is a negative regulatory factor of IL-8. NEAT1 mediates the relocation of SFPQ from the IL-8 promoter region to paraspeckles and activates the transcription of IL-8 (46). Although the exact antiviral mechanism of IL-8 is not clear, the concentration of IL-8 is proportional to the resistance against HIV infection in a macaque model (47). Moreover, NEAT1, as a binding scaffold, maintains integrity of paraspeckles and prevents the export of spliced pre-mRNA to the cytoplasm for translation. During HIV infection, the upregulated NEAT1 sequesters HIV mRNAs within the nucleus and inhibits viral replication (34). Another study shows that NEAT1 is significantly upregulated postinfection with Hantaan virus (HTNV), whereas inhibiting the expression of NEAT1 delays host innate immune responses and promotes viral replication (48). Further investigations indicate that NEAT1 removes and relocates SFPQ to paraspeckles, inducing the expressions of retinoic acid inducible gene I (RIG-I) and DEXDH box helicase (DDX60). Increased expression of DDX60 and RIG-I enhances IFN- $\beta$ production and subsequently suppresses HTNV infection.

The lncRNA Cox2, located at $50 \mathrm{~kb}$ downstream of the Cox2 protein coding gene, regulates the activation and repression of hundreds of genes (36). It has been revealed that 787 genes are repressed by the IncRNA Cox 2 in non-stimulated bone marrow-derived macrophages and 713 genes are expressed following exposure to toll-like receptor (TLR) 1/2 agonist palmitoy3-cysteinyl-seryl-(lysyl $)_{4} \quad\left(\mathrm{Pam}_{3} \mathrm{CSK}_{4}\right) \quad(41)$. The subsequent gene ontology $(\mathrm{GO})$ analysis has revealed that the differentially expressed genes are involved in the regulation of immune responses. The whole transcriptome profiling has proven that Cox 2 is in charge of activating and inducing interferon regulatory factor 7 (IRF7) and IL-10 and repressing TLR1, 3, and 8, which regulates the expression of various genes in both positive and negative regulatory manners (41). Although the exact regulatory mechanisms remain unknown, researchers speculated that the inhibitory actions of Cox 2 could be mediated through binding to heterogeneous nuclear ribonucleoprotein (hnRNP)-A/B and hnRNP-A2/B1. Collectively, lncRNA Cox2 is a key regulatory factor of the circuit adjusting the TLR signaling pathway.

\section{IncRNAs Mediate Other Pathways of the Innate Immune Response}

Tumor necrosis factor-alpha (TNF- $\alpha$ ) is a significant activator of host immune responses to viral infections (49-51). Recently, it has been shown that TNF- $\alpha$ is regulated by a lncRNA, TNF- $\alpha$ 
and hnRNPL- immunoregulatory lncRNA (THRIL) (38). The THRIL is located downstream of BRI3-binding protein (BRI3BP) and partially overlapped with the $3^{\prime}$-terminus of BRI3BP. This lncRNA THRIL is an essential factor for the induction of TNF$\alpha$ gene expression by forming a complex with hnRNPL at the promoter/enhancer region of TNF, resulting in the activation of immune response genes (38). On the other hand, THRIL can also be downregulated by the activated TNF through a negative feedback mechanism. These findings highlight a wider spectrum of lncRNA roles in several cellular processes and warrant future investigations.

\section{IncRNAs Participate in the Regulation of the Expression of Interferon-Stimulated Genes (ISGs)}

ISGs are induced through the IFN signaling pathway and critical for antagonizing viral infections (52). To date, new antiviral ISGs are discovered as antiviral effectors in the innate antiviral responses $(53,54)$. In addition, ISGs have been confirmed to have numerous antiviral functions, such as interfering with and inhibiting viral infections, and limiting viral replication within the cells (52). However, molecular mechanisms of regulation of the ISGs expression are complicated $(53,55)$. Currently, several studies demonstrate that $\ln \mathrm{R}$ NAs are the key regulators of ISGs.

Some viruses can induce the expression of the lncRNA BISPR (BST2 IFN-stimulated positive regulator) through the JAK-STAT pathway, such as influenza virus, vesicular stomatitis virus or hepatitis $\mathrm{C}$ virus (HCV) (56-59). BISPR is located headto-head with the ISG BST2 gene, the BST2 protein can attach viruses to the cells and inhibit viral release $(60,61)$. Knockdown or overexpression of BISPR results in a decrease or increase of BST2 expression, respectively, suggesting that BISPR is critically responsible for the transcription of BST2. BISPR exists mainly in the nucleus and possibly facilitates the transcription initiation of protein-coding genes. As mentioned above, some lncRNAs regulate the chromatin state through recruiting and binding to various chromatin-modifying factors. Likewise, BISPR performs its regulatory function by counteracting the repressive action of polycomb repression complex 2 (PRC2) at the promoter of BST2, and the methyltransferase component of EZH2 is also involved in this mechanism (56). In addition, BISPR overlaps with an enhancer region, indicating that BISPR acts as enhancer-associated RNAs (eRNAs) to promote the formation of enhancerpromoter complex.

A functional lncRNA, called negative regulator of antiviral response (NRAV), is downregulated dramatically during influenza A virus (IAV) infection (62). Overexpression of NRAV in human cells or transgenic mice significantly increases IAV replication and virulence, whereas knockdown of NRAV suppresses IAV replication, indicating that NRAV is involved in antiviral immune responses. A cDNA microarray analysis reveals that many ISGs are downregulated in NRAV-overexpressing cells, such as IFIT2, IFIT3, IFITM3, OASL, and MxA, and these ISGs exert antiviral effects through multiple mechanisms (63-66). A subsequent study indicates that NRAV negatively regulates the initial transcription rates of IFITM3 and MxA through altering histone modifications (active $\mathrm{H} 3 \mathrm{~K} 4 \mathrm{me} 3$ and repressive
$\mathrm{H} 3 \mathrm{~K} 27 \mathrm{me} 3$ ) on the promoters, and the spatial structure of NRAV is necessary for its regulatory function (62).

The lncRNA CMPK2 is located proximally to the ISGs CMPK2, which is mapped to chr2p25.2 (chr2:6,968,644$6,980,595)$. The lncRNA CMPK2 can be upregulated significantly by IFN- $\alpha$ or IFN- $\gamma(25,67)$. Knockdown of lncRNA CMPK2 in hepatocytes results in remarkable reduction in HCV replication and increases expression of some antiviral ISGs, suggesting that the lncRNA CMPK2 is a critical repressor of ISGs and a lncRNA-mediated negatively regulatory mechanism may exist. In addition, the level of the lncRNA CMPK2 is dramatically higher in the liver of $\mathrm{HCV}$-infected patients compared with healthy donors, indicating that the lncRNA CMPK2 also plays a regulatory role in viral infections in vivo (25), whereas overexpression of the lncRNA CMPK2 inhibits the transcription of ISGs, such as CMPK2 and viperin. Interestingly, some ISGs located far from the lncRNA CMPK2 in the genome can also be repressed, such as ISG15, IFIT1, IFIT3, CXCL10, MxA, and IFITM1. Nevertheless, a few of ISGs seem to inhibit the transcription of the lncRNA CMPK2, including IFIT1 and Mx1. However, the impact of silencing of the lncRNA CMPK2 on ISG levels is not consistent with other IFN-stimulated negative regulatory factors, such as activating signal cointegrator 1 complex subunit 3 . Thus, it is considered that the regulatory mechanism of lncRNA CMPK2 may be similar to other lncRNAs, such as NRAV. Similarly, lncRNA CMPK2 interacts with transcription factors or chromatin to form complexes to regulate the gene expression.

The lncRNA\#32 is located on human chromosome 7p13 and overlaps the 3 '-terminus of the HECT, C3, and WW domain containing E3 ubiquitin protein ligase 1 (HECW1) (68). Silencing lncRNA\#32 significantly reduces the expression level of some ISGs and chemokines, including IRF7, chemokine (C-C motif) ligand 5 (CCL5), CXCL11, OASL, RSAD2, and IP-10, resulting in susceptibility to encephalomyocarditis virus (EMCV) infection. In contrast, the overexpression of lncRNA\#32 dramatically suppressed EMCV replication, indicating that lncRNA\#32 positively regulates the host antiviral response (68). The expression of OASL is induced by IFN- $\beta$, whereas the expression of $\operatorname{lncRNA\# 32}$ is repressed by IFN- $\beta$ in a dose-dependent manner. lncRNA\#32 positively regulates the expression of ISGs through its interaction with activating transcription factor 2 (ATF2). The ATF2-binding region deletion mutant of $\operatorname{lncRNA} \# 32$ does not induce IP-10 expression. The research also finds that heterogeneous nuclear ribonucleoprotein $\mathrm{U}$ (hnRNPU) maintains the expression of these ISGs by binding to and stabilizing lncRNA\#32. These findings highlight the possibility that the hnRNPU-lncRNA\#32 complex may target promoters of ISGs to promote the transcription (Figure 3).

Taken together, current understandings propose the nature and breadth of IncRNAs in the regulation of ISGs, which define the first line of defense against pathogens. While a significant baseline has been made, extensive future studies are required to underpin this important aspect of host-pathogen interactions along with their impacts on virus biology and host responses. 


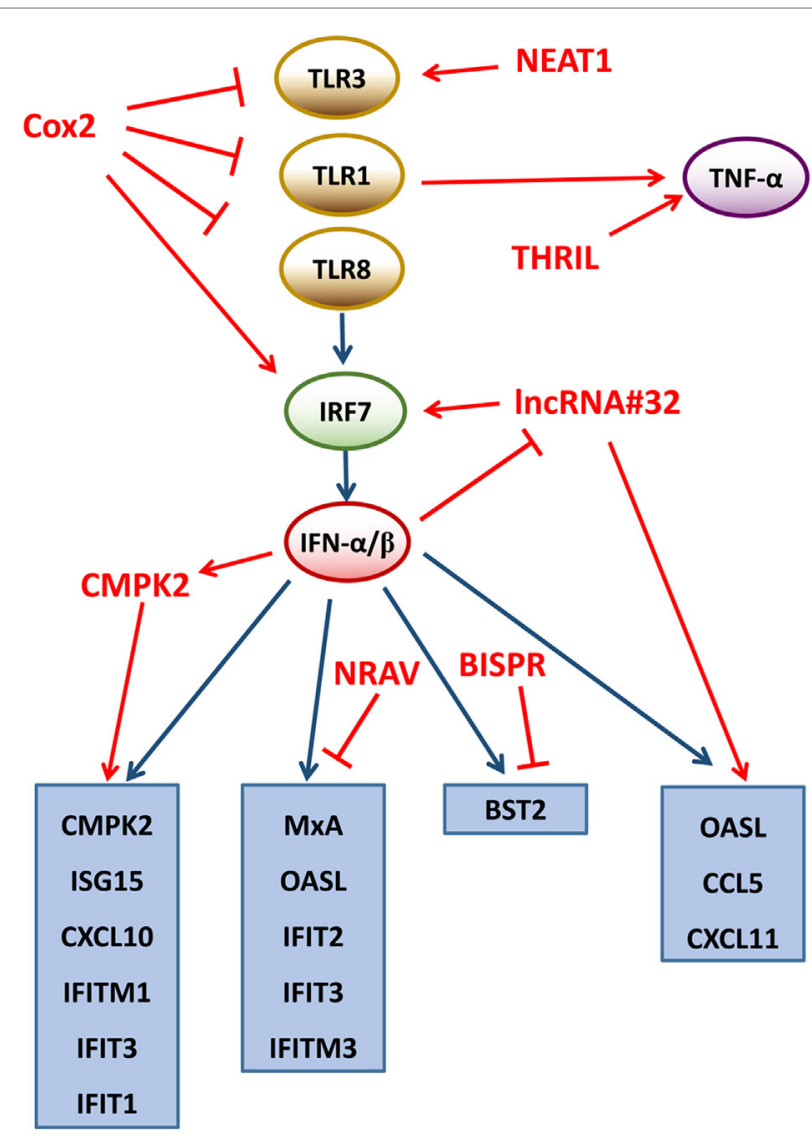

FIGURE $3 \mid$ IncRNAs regulate the immune responses. Proteins and IncRNAs involved in the immune responses are shown in black and red, respectively. Inhibition is shown with a T-shaped line. Activation is depicted with an arrow. NEAT1, nuclear enriched abundant transcript 1; THRIL, TNF- $\alpha$ and hnRNPL-related immunoregulatory IncRNA; NRAV, negative regulator of antiviral response; BISPR, BST2 IFN-stimulated positive regulator; CMPK2, cytidine monophosphate kinase 2; TLR1, 3, and 8, toll-like receptors 1, 3, and 8; IRF7, interferon regulatory factor 7 ; TNF- $\alpha$, tumor necrosis factoralpha; IFN- $\alpha / \beta$, interferon-alpha/beta; ISG15, interferon-stimulated gene 15; CXCL10 and 11, chemokine (C-X-C motif) ligand 10 and 11; IFIT1, 2, and 3, interferon-induced proteins with tetratricopeptide repeats 1, 2, and 3; IFITM 1 and 3, interferon-induced transmembrane protein 1 and 3; OASL, oligoadenylate synthetase-like; MxA, myxovirus resistance protein A; BST2, bone marrow stromal cell antigen 2; CCL5, chemokine (C-C motif) ligand 5; IncRNA, long non-coding RNA.

\section{IncRNAs Are Involved in the Adaptive Immune Response}

Although the existence of lncRNAs in T cells has been known for years, such as growth-arrest-specific transcript 5 (Gas5) and non-coding transcript in $\mathrm{CD} 4^{+} \mathrm{T}$ cells, the IncRNA screening has recently been conducted in $\mathrm{CD}^{+} \mathrm{T}$ cells (69). A total of 1,524 lncRNAs were identified from 42 mouse $\mathrm{T}$ cell subsets using a microarray assay and some of them were lymphoid-specific lncRNAs, which were increased during $\mathrm{CD}^{+} \mathrm{T}$ cell activation and differentiation into effector $\mathrm{T}$ cells (70). At the differentiation state of $\mathrm{CD} 4^{+} \mathrm{T}$ cells to $\mathrm{T}_{\mathrm{H}} 1$ or $\mathrm{T}_{\mathrm{H}} 2$ subsets, $\mathrm{T}_{\mathrm{H}} 1$-related transcription factors, such as STAT4 and T-box transcription factor, can induce the expression of some $\mathrm{T}_{\mathrm{H}} 1$-specific lncRNAs. Likewise, $\mathrm{T}_{\mathrm{H}} 2$ transcription factor STAT6 regulates $\mathrm{T}_{\mathrm{H}} 2$-specific $\operatorname{lncRNAs}$ expression. In addition, lncRNA Gas5 represses T cell proliferation. Overexpression of Gas5 inhibits cell-cycle progression and initiates the cell apoptosis signaling pathways (71). Limited studies have been conducted to investigate the roles of lncRNAs in adaptive immune responses; however, current evidences propose crucial roles of lncRNAs in regulation of adaptive immunity and thus warrant future investigations.

\section{HOST IncRNAs ARE HIJACKED BY VARIOUS VIRUSES}

Host lncRNAs have been confirmed as positive or negative antiviral regulators in the immune response; surprisingly, a few of host lncRNAs can be induced and hijacked by certain viruses to establish persistent infections. This is likely due to the mutual adaptability of hosts and viruses for millions of years.

The lncRNA NeST, also known as Tmevpg1 or IfngAS1, is located adjacent to the IFN- $\gamma$ gene in both humans and mice that can positively regulate the expression of IFN- $\gamma$ (72). NeST can bind to WD repeat-containing protein 5 (WDR5), a component of histone $\mathrm{H} 3$ lysine 4 (H3K4) methyltransferase complex, and alter histone 3 methylation at the IFN- $\gamma$ locus, resulting in the IFN- $\gamma$ expression (72). In addition, the transcription of both mouse and human NeST gene is dependent on NF- $\mathrm{KB}$ and transcription factors STAT4 and T-bet $(73,74)$. An earlier study has shown that NeST is specially expressed in $\mathrm{T}_{\mathrm{H}} 1 \mathrm{CD} 4^{+} \mathrm{T}$ cells and is considered to be associated with immune response (73). Another similar study has indicated that NeST facilitates Theiler's virus infection (75), which is verified using B10.S and SJL/L mouse models. The SJL/L mice with NeST gene show increased IFN- $\gamma$ expression in activated $\mathrm{CD} 8^{+} \mathrm{T}$ cells, leading to persistent infection of Theiler's virus, and the NeST gene-knockout B10.S mice can clear the virus by its own immune system. The transgenic B10.S mice carrying the allele of NeST are unable to resist the viral infection either. Thus, Theiler's virus establishes persistent infections by hijacking the host lncRNA NeST.

The lncRNA NRON is required to regulate the activity of nuclear factor of activated T cells (NFAT) by forming a ribonucleoprotein complex with NFAT kinases and expression of this lncRNA is significantly altered following HIV-1 infection (45, 76-79). The regulation of NRON expression during the HIV-1 life cycle is complex. The level of NRON is reduced by the HIV-1 early accessory protein Nef and the dephosphorylated NFAT can be translocated to the nucleus and activates the expression of several genes of HIV (78). Knockdown of NRON enhances virus replication through increasing the activity of NFAT. However, high-level expression of NRON is induced by the HIV-1 accessory protein $\mathrm{Vpu}$ at the late stages of HIV infection, resulting in viral release and apoptosis. It has been demonstrated that the expression level of NRON is modulated by the HIV-1 Nef and Vpu proteins at different times postinfection to fit the virus life cycle. This finding explains how HIV regulates the host lncRNA NRON to facilitate viral infection.

IncRNA-ACOD1, located near the ACOD1 protein-coding gene, can be induced by various viruses, including Sendai virus 
$(\mathrm{SeV})$, vesicular stomatitis virus (VSV), herpes simplex virus (HSV), and vaccinia virus (VACV) (80). In addition, IncRNAACOD1 is an IFN- $\alpha$-independent lncRNA, of which expression is regardless of IFN- $\alpha$ receptor deficiency and IFN- $\alpha$ stimulation. Knockdown of lncRNA-ACOD1 significantly reduces viral load of VSV in macrophages and VSV replication is remarkably reduced in the IncRNA-ACOD1-deficient mice, indicating that the IncRNA promotes virus replication (80). Microarray transcriptome analysis shows that the IncRNA-ACOD1 deficiency leads to changes in the expressions of many metabolism-related genes, indicating the potential role of the lncRNA in regulation of metabolism upon viral infection. RNA immunoprecipitation assay suggests that lncRNA-ACOD1 directly binds to the metabolic enzyme glutamic-oxaloacetic transaminase 2 (GOT2) near the substrate niche, enhancing its catalytic activity. It has been shown that IncRNA-ACOD1 overexpression promotes viral replication in control cells, while has no effect in GOT2knockdown cells. Taken together, these results demonstrate that lncRNA-ACOD1 facilitates viral replication through promoting GOT2 activity.

\section{VIRALLY ENCODED IncRNAs INHIBIT ANTIVIRAL RESPONSES}

The existence of virus-encoded lncRNAs has been identified for years $(81,82)$. However, only recently, their roles in virus pathobiology and host responses have been explored. The viral lncRNAs are generally transcribed from RNA polymerase II or III, and some of lncRNAs can even be polyadenylated, similar to host mRNA $(11,83)$. Interestingly, some viral lncRNAs even need unique maturation steps using host cell transcription machineries.

A polyadenylated nuclear RNA (IncRNA PAN) expressed by Kaposi's sarcoma-associated herpesvirus is localized within the cell nucleus and accumulated largely during lytic infection. Several studies demonstrate that PAN represses host gene transcription through a variety of mechanisms. Interferon regulatory factor 4 (IRF4) is a transcription factor that can bind to and transactivate the IL-4 promoter along with PU.1 (84). However, the expression of PAN interferes with the transcription of IL- 4 through preventing PU.1 binding to IL-4 promoter (85). In addition, the results also suggest that PAN decreases the expression of several immune regulators, including IL-18, RNase L, IFN-16, and IFN- $\gamma$. This mechanism is closely connected to the extensive binding capacity of PAN and host transcriptional proteins, such as histones $\mathrm{H} 1$ and $\mathrm{H} 2 \mathrm{~A}$, and mitochondrial and cellular single-stranded binding proteins. Another similar study indicates that PAN suppresses the expression of host antiviral genes by activating the PRC2 (83). Besides broadly inhibiting actions of immunity-related genes, PAN also participates in regulating the virus life cycle. In this context, it has been shown that PAN is able to bind to ubiquitously transcribed tetratricopeptide repeat X chromosome (UTX) and jumonji domain containing 3 (JMJD3) to remove the H3K23me3 from the viral genome, resulting in the change of virus life cycle from latent to lytic infection $(86,87)$. In addition, PAN interacts with the latency-associated nuclear antigen protein (LANA) to maintain latent infection. Collectively, the viral lncRNA PAN regulates both host and viral gene expression to inhibit antiviral responses and regulate virus life cycle.

Another lncRNA Beta2.7, transcribed from the human cytomegalovirus genome, exists at the early stages of viral infection $(88,89)$. Beta2.7 and GRIM19 (gene associated with retinoid/ IFN-induced mortality-19) are combined together to form a subunit of mitochondrial complex I, which is key for stabilizing the mitochondrial membrane potential, leading to continued production of adenosine triphosphate, which is critical for the completion of the virus life cycle (90-92). Beta2.7 may also protect mitochondrial complex I against stress-induced apoptosis and prevent neuron death.

The $5^{\prime}-3^{\prime}$ exonuclease Xrn 1 functions in mRNA decay as well as degradation of flavivirus genomic RNA $(84,93)$. Most of the RNAs, even the ones with strong secondary or tertiary structures, cannot resist Xrn1 degradation. Surprisingly, the subgenomic flavivirus RNAs (sfRNAs), generated from viral genome, accumulate to a high level in cells and repress the activation of Xrn1 (94-96). A further study demonstrates that the lncRNA sfRNAs are transcribed at the $3^{\prime}$-terminus of flavivirus genome. Based on the special stem-loop structure, the lncRNA sfRNAs bind to the Xrn1 and inhibit its cascade function. Moreover, Xrn1 can also be used to form new $5^{\prime}$-terminus of transcripts to improve viral gene expression via the generation of the lncRNA sfRNAs (95). The lncRNAs from hepaciviruses (e.g., HCV) and pestiviruses (e.g., bovine viral diarrhea virus) are shorter than those from arthropod-borne flaviviruses, which implies that they may play unique roles in the virus life cycle. The transcription and function of the lncRNA sfRNAs indicate that flaviviruses repress host immune system with virus-encoded lncRNAs (Table 1).

\section{CONCLUDING REMARKS AND PROSPECTS}

Formerly, lncRNAs were considered as non-functional gene transcripts in cells and the studies on host-virus interactions were mainly focus on the genomic DNA and proteins of hosts or viruses. However, in the past few years, powerful evidence supports that some lncRNAs from hosts or viruses are actively involved in host-virus interactions. On one hand, host-encoded lncRNAs are supposed to exert antiviral functions via different immune response processes, including innate and adaptive immune responses and ISG expression through completely different mechanisms. On the other hand, viruses seem to hijack host lncRNAs or to exploit viral lncRNAs for inhibition of antiviral responses and virus persistence. Thus, besides DNA and proteins, lncRNAs are a new kind of actors in host immune defense and virus survival.

Here, we raise a question: how to identify functional lncRNAs? To obtain the potential lncRNAs, conventionally researchers analyze the transcriptome and screen the differential expression of mRNAs and lncRNAs induced by viral infections. However, a leading challenge is how to separate lncRNAs from mRNAs in large-scale transcriptome data, since hundreds or even thousands of differentially expressed lncRNAs will be obtained using 
TABLE 1 | Characteristics of IncRNAs involved in host-virus interactions.

\begin{tabular}{|c|c|c|c|c|}
\hline $\begin{array}{l}\text { Functions } \\
\text { of IncRNAs }\end{array}$ & Names & Mechanisms & Sources & References \\
\hline \multirow{8}{*}{$\begin{array}{l}\text { Antiviral } \\
\text { responses }\end{array}$} & NeST & NeST interacts with WDR5 to alter histone 3 methylation at the IFN- $\gamma$ locus to induce the IFN- $\gamma$ expression & Host & $(72)$ \\
\hline & NRAV & NRAV inhibits the initial transcription of IFITM3 and MXA by regulating the histone modifications of these ISG genes & Host & (62) \\
\hline & IncRNA\#32 & $\begin{array}{l}\text { IncRNA\#32 significantly increases the expression of IRF7, CCL5, CXCL11, OASL, RSAD2, and IP-10 through its } \\
\text { interaction with ATF2 and hnRNPU }\end{array}$ & Host & (68) \\
\hline & BISPR & BISPR induces the transcription of BST2 gene in trans by counteracting the repressive action of PRC2 & Host & (56) \\
\hline & Cox2 & $\begin{array}{l}\text { Cox2, induced by TLR, can interact with hnRNP-A/B and hnRNP-A2/B1 to mediate the immune responses in both } \\
\text { positive and negative regulatory signaling pathways }\end{array}$ & Host & $(41)$ \\
\hline & THRIL & $\begin{array}{l}\text { THRIL binds to hnRNPL and TNF promoter/enhancer region to induce TNF- } \alpha \text { expression and is downregulated } \\
\text { by TNF activation through a negative feedback mechanism }\end{array}$ & Host & (38) \\
\hline & NEAT1 & $\begin{array}{l}\text { NEAT1 activates the transcription of IL-8, RIG-I, and DDX60 through removal of the transcriptional inhibitory effects } \\
\text { of SFPQ from promoter region by relocating SFPQ to paraspeckles }\end{array}$ & Host & $(34,44,46)$ \\
\hline & CMPK2 & $\begin{array}{l}\text { IncRNA CMPK2, as a negative regulatory factor in ISGs response, is involved in the regulation of ISGs transcription } \\
\text { by forming RNA-protein complexes with chromatin remodeling or transcription factors }\end{array}$ & Host & (25) \\
\hline \multirow[t]{6}{*}{$\begin{array}{l}\text { Virus } \\
\text { infections }\end{array}$} & NRON & $\begin{array}{l}\text { The HIV-1 Nef and Vpu proteins reduce or increase the expression of NRON at different times postinfection to } \\
\text { regulate the virus life cycle, resulting in persistent infection }\end{array}$ & Host & $(77)$ \\
\hline & $\mathrm{NeST}$ & $\begin{array}{l}\text { Overexpression of NeST has been shown to increase the persistence of Theiler's virus and reduce the host } \\
\text { resistance }\end{array}$ & Host & (75) \\
\hline & $\begin{array}{l}\text { IncRNA- } \\
\text { ACOD1 }\end{array}$ & $\begin{array}{l}\text { IncRNA-ACOD1 is induced during viral infection and facilitates viral replication through promoting the catalytic } \\
\text { activity of GOT2 }\end{array}$ & Host & (80) \\
\hline & PAN & $\begin{array}{l}\text { PAN is a key regulator in controlling gene expression by multiple mechanisms. Many immunity-related genes, } \\
\text { such as IL-4, IFN- } \gamma \text {, IL-18, and IFN- } \alpha \text {, are regulated by InCRNA PAN. In addition, PAN participates in regulating the } \\
\text { virus life cycle through removing the suppressive H3K23me3 from the viral genome and interacting with LANA to } \\
\text { maintain latent infection }\end{array}$ & Virus & $(83-87)$ \\
\hline & Beta2.7 & $\begin{array}{l}\text { Beta2.7 and GRIM19 are combined together to form a subunit of mitochondrial complex I, leading to continued } \\
\text { production of adenosine triphosphate }\end{array}$ & Virus & (92) \\
\hline & sfRNAs & Based on the special secondary structure, sfRNAs bind to Xrn1 and inhibit its degradation of flaviviral genomic RNA & Virus & $(94,95)$ \\
\hline
\end{tabular}

IncRNAs, Iong non-coding RNAs; WDR5, WD repeat-containing protein 5; IFN- $\gamma$, interferon- $\gamma$; NRAV, negative regulator of antiviral response; ISG, interferon-stimulated gene; IRF7, interferon regulatory factor 7; BISPR, BST2 IFN-stimulated positive regulator; hnRNPU, heterogeneous nuclear ribonucleoprotein U; ATF2, activating transcription factor 2; PRC2, polycomb repression complex 2; TLR, toll-like receptor; hnRNP, heterogeneous nuclear ribonucleoprotein; THRIL, TNF- $\alpha$ and hnRNPL-related immunoregulatory IncRNA; NEAT1, nuclear enriched abundant transcript 1; HIV, human immunodeficiency virus; GOT2, glutamic-oxaloacetic transaminase 2; sfRNAs, subgenomic flavivirus RNAs.

RNA-seq data, making it laborious to identify functionallncRNAs. Indeed, unlike mRNAs, the sequences of lncRNAs usually display poor evolutionary conservation among different species, thus it is difficult to use conventional bioinformatic tools to predict their functions. In addition, the sequences of $\operatorname{lncRNAs}$ are yet to be determined in most species. In spite of these limitations, many lncRNAs from viruses or hosts have been disclosed in recent years. We propose to establish bioinformatics pipelines to genetically annotate lncRNAs by incorporating our current understandings on the functions of lncRNAs in the future.

Since $\operatorname{lncRNAs}$ are associated with DNA, mRNA or proteins, it is worth thinking about the possible existence of potential links between lncRNAs and miRNAs. This speculation is supported by some studies that lncRNAs can act as efficient miRNA "sponges" to reduce miRNA levels or through binding to primary miRNAs to repress miRNA maturation $(97,98)$. However, the discovery about the functions of sncRNAs is scarcely reported in viral infections or host-virus interactions. Up to now, the interactions between miRNA and lncRNAs are a freshly new frontier research area.

Currently, relatively complete lncRNA databases have been established only for human and model animal species (mouse and rat). However, based on the current findings, we believe that lncRNA databases for broader species will facilitate the study on natures and dynamics of lncRNAs-mediated antiviral responses and regulation of the virus life cycle.

In conclusion, growing evidence suggests that additional hosts- or viral-origin lncRNAs remain undiscovered, and systematic and novel probing approaches are required to characterize functional lncRNAs and identify clinically relevant lncRNAs with broader antiviral characteristics.

\section{AUTHOR CONTRIBUTIONS}

$\mathrm{X}-\mathrm{YM}$ is the major contributor of the review. YL, MNA, YS, YG, $\mathrm{HZ}$ and MM participate in the modification of the article. H-JQ conceived and revised the paper.

\section{ACKNOWLEDGMENTS}

This work was supported by National Natural Science Foundation of China (no. 31700139 and 31402194) and China Postdoctoral Science Foundation (no. 2016M591313). We appreciate Drs. Muhammad Abid and Teshale Teklue for editing the manuscript. 


\section{REFERENCES}

1. Carninci P, Kasukawa T, Katayama S, Gough J, Frith MC, Maeda N, et al. Genome science: the transcriptional landscape of the mammalian genome. Science (2005) 309(5740):1559-63. doi:10.1126/science.1112014

2. Okazaki Y, Furuno M, Kasukawa T, Adachi J, Bono H, Kondo S, et al. Analysis of the mouse transcriptome based on functional annotation of 60,770 full-length cDNAs. Nature (2002) 420(6915):563-73. doi:10.1038/ nature 01266

3. ENCODE Project Consortium. An integrated encyclopedia of DNA elements in the human genome. Nature (2012) 489(7414):57-74. doi:10.1038/ nature 11247

4. Consortium EP, Birney E, Stamatoyannopoulos JA, Dutta A, Guigo R, Gingeras TR, et al. Identification and analysis of functional elements in $1 \%$ of the human genome by the ENCODE pilot project. Nature (2007) 447(7146):799-816. doi:10.1038/nature05874

5. Cech TR, Steitz JA. The noncoding RNA revolution-trashing old rules to forge new ones. Cell (2014) 157(1):77-94. doi:10.1016/j.cell.2014.03.008

6. Katsarou K, Rao ALN, Tsagris M, Kalantidis K. Infectious long non-coding RNAs. Biochimie (2015) 117:37-47. doi:10.1016/j.biochi.2015.05.005

7. Prasanth KV, Spector DL. Eukaryotic regulatory RNAs: an answer to the 'genome complexity' conundrum. Genes Dev (2007) 21(1):11-42. doi:10.1101/ gad.1484207

8. Amaral PP, Dinger ME, Mercer TR, Mattick JS. The eukaryotic genome as an RNA machine. Science (2008) 319(5871):1787-9. doi:10.1126/science.1155472

9. Gong C, Maquat LE. IncRNAs transactivate STAU1-mediated mRNA decay by duplexing with 3' UTRs via Alu elements. Nature (2011) 470(7333): 284-8. doi:10.1038/nature09701

10. Kapranov P, Cheng J, Dike S, Nix DA, Duttagupta R, Willingham AT, et al. RNA maps reveal new RNA classes and a possible function for pervasive transcription. Science (2007) 316(5830):1484-8. doi:10.1126/science.1138341

11. Fortes P, Morris KV. Long noncoding RNAs in viral infections. Virus Res (2016) 212:1-11. doi:10.1016/j.virusres.2015.10.002

12. Heward JA, Lindsay MA. Long non-coding RNAs in the regulation of the immune response. Trends Immunol (2014) 35(9):408-19. doi:10.1016/j.it. 2014.07.005

13. Derrien T, Johnson R, Bussotti G, Tanzer A, Djebali S, Tilgner H, et al. The GENCODE v7 catalog of human long noncoding RNAs: analysis of their gene structure, evolution, and expression. Genome Res (2012) 22(9):1775-89. doi:10.1101/gr.132159.111

14. Caley DP, Pink RC, Trujillano D, Carter DR. Long noncoding RNAs, chromatin, and development. ScientificWorld Journal (2010) 10:90-102. doi:10.1100/ tsw. 2010.7

15. Djebali S, Davis CA, Merkel A, Dobin A, Lassmann T, Mortazavi A, et al. Landscape of transcription in human cells. Nature (2012) 489(7414):101-8. doi:10.1038/nature11233

16. Ponjavic J, Ponting CP, Lunter G. Functionality or transcriptional noise? Evidence for selection within long noncoding RNAs. Genome Res (2007) 17(5):556-65. doi:10.1101/gr.6036807

17. Ponting CP, Oliver PL, Reik W. Evolution and functions of long noncoding RNAs. Cell (2009) 136(4):629-41. doi:10.1016/j.cell.2009.02.006

18. Huarte M, Rinn JL. Large non-coding RNAs: missing links in cancer? Hum Mol Genet (2010) 19(R2):R152-61. doi:10.1093/hmg/ddq353

19. Wang KC, Chang HY. Molecular mechanisms of long noncoding RNAs. Mol Cell (2011) 43(6):904-14. doi:10.1016/j.molcel.2011.08.018

20. Gupta RA, Shah N, Wang KC, Kim J, Horlings HM, Wong DJ, et al. Long non-coding RNA HOTAIR reprograms chromatin state to promote cancer metastasis. Nature (2010) 464(7291):1071-6. doi:10.1038/nature08975

21. Yoon JH, Abdelmohsen K, Gorospe M. Posttranscriptional gene regulation by long noncoding RNA. J Mol Biol (2013) 425(19):3723-30. doi:10.1016/ j.jmb.2012.11.024

22. Sun BK, Deaton AM, Lee JT. A transient heterochromatic state in Xist preempts X inactivation choice without RNA stabilization. Mol Cell (2006) 21(5):617-28. doi:10.1016/j.molcel.2006.01.028

23. Carnero E, Barriocanal M, Segura V, Guruceaga E, Prior C, Borner K, et al. Type I interferon regulates the expression of long non-coding RNAs. Front Immunol (2014) 5:548. doi:10.3389/fimmu.2014.00548
24. Josset L, Tchitchek N, Gralinski LE, Ferris MT, Eisfeld AJ, Green RR, et al. Annotation of long non-coding RNAs expressed in collaborative cross founder mice in response to respiratory virus infection reveals a new class of interferon-stimulated transcripts. RNA Biol (2014) 11(7):875-90. doi:10.4161/ rna.29442

25. Kambara H, Niazi F, Kostadinova L, Moonka DK, Siegel CT, Post AB, et al. Negative regulation of the interferon response by an interferon-induced long non-coding RNA. Nucleic Acids Res (2014) 42(16):10668-80. doi:10.1093/ nar/gku713

26. Seila AC, Calabrese JM, Levine SS, Yeo GW, Rahl PB, Flynn RA, et al. Divergent transcription from active promoters. Science (2008) 322(5909):1849-51. doi:10.1126/science.1162253

27. Salmena L, Poliseno L, Tay Y, Kats L, Pandolfi PP. A ceRNA hypothesis: the Rosetta stone of a hidden RNA language? Cell (2011) 146(3):353-8. doi:10.1016/j.cell.2011.07.014

28. Tay Y, Kats L, Salmena L, Weiss D, Tan SM, Ala U, et al. Coding-independent regulation of the tumor suppressor PTEN by competing endogenous mRNAs. Cell (2011) 147(2):344-57. doi:10.1016/j.cell.2011.09.029

29. Mercer TR, Dinger M, Mattick JS. Long non-coding RNAs: insights into functions. Nat Rev Genet (2009) 10(3):155-9. doi:10.1038/nrg2521

30. Luo S, Lu JY, Liu L, Yin Y, Chen C, Han X, et al. Divergent lncRNAs regulate gene expression and lineage differentiation in pluripotent cells. Cell Stem Cell (2016) 18(5):637-52. doi:10.1016/j.stem.2016.01.024

31. Katayama S, Tomaru Y, Kasukawa T, Waki K, Nakanishi M, Nakamura M, et al. Antisense transcription in the mammalian transcriptome. Science (2005) 309(5740):1564-6. doi:10.1126/science.1112009

32. Peng X, Gralinski L, Armour CD, Ferris MT, Thomas MJ, Proll S, et al. Unique signatures of long noncoding RNA expression in response to virus infection and altered innate immune signaling. MBio (2010) 1(5):e00206-10. doi: $10.1128 / \mathrm{mBio} .00206-10$

33. Sonkoly E, Bata-Csorgo Z, Pivarcsi A, Polyanka H, Kenderessy-Szabo A, Molnar G, et al. Identification and characterization of a novel, psoriasis susceptibility-related noncoding RNA gene. PRINS J Biol Chem (2005) 280(25):24159-67. doi:10.1074/jbc.M501704200

34. Zhang Q, Chen CY, Yedavalli VS, Jeang KT. NEAT1 long noncoding RNA and paraspeckle bodies modulate HIV-1 posttranscriptional expression. MBio (2013) 4(1):e00596-12. doi:10.1128/mBio.00596-12

35. Ahanda ML, Ruby T, Wittzell H, Bed'Hom B, Chausse AM, Morin V, et al. Non-coding RNAs revealed during identification of genes involved in chicken immune responses. Immunogenetics (2009) 61(1):55-70. doi:10.1007/ s00251-008-0337-8

36. Razooky BS, Obermayer B, O’May JB, Tarakhovsky A. Viral infection identifies micropeptides differentially regulated in smORF-containing lncRNAs. Genes (Basel) (2017) 8(8):206-16. doi:10.3390/genes8080206

37. Guttman M, Amit I, Garber M, French C, Lin MF, Feldser D, et al. Chromatin signature reveals over a thousand highly conserved large non-coding RNAs in mammals. Nature (2009) 458(7235):223-7. doi:10.1038/nature07672

38. Li Z, Chao TC, Chang KY, Lin N, Patil VS, Shimizu C, et al. The long noncoding RNA THRIL regulates TNF-alpha expression through its interaction with hnRNPL. Proc Natl Acad Sci U S A (2014) 111(3):1002-7. doi:10.1073/ pnas.1313768111

39. Rapicavoli NA, Qu K, Zhang J, Mikhail M, Laberge RM, Chang HY. A mammalian pseudogene lncRNA at the interface of inflammation and antiinflammatory therapeutics. Elife (2013) 2:e00762. doi:10.7554/eLife.00762

40. Wang $\mathrm{P}$, Xue Y, Han Y, Lin L, Wu C, Xu S, et al. The STAT3-binding long noncoding RNA lnc-DC controls human dendritic cell differentiation. Science (2014) 344(6181):310-3. doi:10.1126/science.1251456

41. Carpenter S, Aiello D, Atianand MK, Ricci EP, Gandhi P, Hall LL, et al. A long noncoding RNA mediates both activation and repression of immune response genes. Science (2013) 341(6147):789-92. doi:10.1126/science.1240925

42. Zhang J, Sun P, Gan L, Bai W, Wang Z, Li D. Genome-wide analysis of long noncoding RNA profiling in PRRSV-infected PAM cells by RNA sequencing. Sci Rep (2017) 7(1):4952-62. doi:10.1038/s41598-017-05279-Z

43. Garmire LX, Garmire DG, Huang W, Yao J, Glass CK, Subramaniam S. A global clustering algorithm to identify long intergenic non-coding RNA with applications in mouse macrophages. PLoS One (2011) 6(9):e24051. doi:10.1371/journal.pone.0024051 
44. Clemson CM, Hutchinson JN, Sara SA, Ensminger AW, Fox AH, Chess A, et al. An architectural role for a nuclear noncoding RNA: NEAT1 RNA is essential for the structure of paraspeckles. Mol Cell (2009) 33(6):717-26. doi:10.1016/j.molcel.2009.01.026

45. Lazar DC, Morris KV, Saayman SM. The emerging role of long noncoding RNAs in HIV infection. Virus Res (2016) 212:114-26. doi:10.1016/ j.virusres.2015.07.023

46. Imamura K, Imamachi N, Akizuki G, Kumakura M, Kawaguchi A, Nagata K, et al. Long noncoding RNA NEAT1-dependent SFPQ relocation from promoter region to paraspeckle mediates IL8 expression upon immune stimuli. Mol Cell (2014) 53(3):393-406. doi:10.1016/j.molcel.2014.01.009

47. Promadej-Lanier N, Hanson DL, Srinivasan P, Luo W, Adams DR, Guenthner PC, et al. Resistance to simian HIV infection is associated with high plasma interleukin-8, RANTES and eotaxin in a macaque model of repeated virus challenges. J Acquir Immune Defic Syndr (2010) 53(5):574-81. doi:10.1097/QAI.0b013e3181d3521f

48. Ma H, Han P, Ye W, Chen H, Zheng X, Cheng L, et al. The long noncoding RNA NEAT1 exerts anti-hantaviral effects by acting as positive feedback for RIG-I signaling. J Virol (2017) 91(9):2250-2216. doi:10.1128/JVI.02250-16

49. Puthothu B, Bierbaum S, Kopp MV, Forster J, Heinze J, Weckmann M, et al. Association of TNF-alpha with severe respiratory syncytial virus infection and bronchial asthma. Pediatr Allergy Immunol (2009) 20(2):157-63. doi:10.1111/j.1399-3038.2008.00751.x

50. Torigo S, Ihara T, Kamiya H. IL-12, IFN-gamma, and TNF-alpha released from mononuclear cells inhibit the spread of varicella-zoster virus at an early stage of varicella. Microbiol Immunol (2000) 44(12):1027-31. doi:10.1111/j. 1348-0421.2000.tb02599.x

51. Neuzil KM, Tang YW, Graham BS. Protective role of TNF-alpha in respiratory syncytial virus infection in vitro and in vivo. Am J Med Sci (1996) 311(5):201-4. doi:10.1016/S0002-9629(15)41695-7

52. Poynter SJ, DeWitte-Orr SJ. Fish interferon-stimulated genes: the antiviral effectors. Dev Comp Immunol (2016) 65:218-25. doi:10.1016/j.dci.2016.07.011

53. Schneider WM, Chevillotte MD, Rice CM. Interferon-stimulated genes: a complex web of host defenses. Annu Rev Immunol (2014) 32:513-45. doi:10.1146/annurev-immunol-032713-120231

54. Zhang YB, Gui JF. Molecular regulation of interferon antiviral response in fish. Dev Comp Immunol (2012) 38(2):193-202. doi:10.1016/j.dci.2012.06.003

55. Haller O, Kochs G. Interferon-induced mx proteins: dynamin-like GTPases with antiviral activity. Traffic (2002) 3(10):710-7. doi:10.1034/j.1600-0854. 2002.31003.x

56. Kambara H, Gunawardane L, Zebrowski E, Kostadinova L, Jobava R, Krokowski D, et al. Regulation of interferon-stimulated gene BST2 by a IncRNA transcribed from a shared bidirectional promoter. Front Immunol (2014) 5:676. doi:10.3389/fimmu.2014.00676

57. Barriocanal M, Carnero E, Segura V, Fortes P. Long non-coding RNA BST2/ BISPR is induced by IFN and regulates the expression of the antiviral factor tetherin. Front Immunol (2014) 5:655. doi:10.3389/fimmu.2014.00655

58. Dafa-Berger A, Kuzmina A, Fassler M, Yitzhak-Asraf H, Shemer-Avni Y, Taube R. Modulation of hepatitis $\mathrm{C}$ virus release by the interferon-induced protein BST-2/tetherin. Virology (2012) 428(2):98-111. doi:10.1016/j.virol. 2012.03.011

59. Neil SJ, Zang T, Bieniasz PD. Tetherin inhibits retrovirus release and is antagonized by HIV-1 Vpu. Nature (2008) 451(7177):425-30. doi:10.1038/ nature 06553

60. Rinn JL, Chang HY. Genome regulation by long noncoding RNAs. Annu Rev Biochem (2012) 81:145-66. doi:10.1146/annurev-biochem-051410-092902

61. Rinn JL. IncRNAs: linking RNA to chromatin. Cold Spring Harb Perspect Biol (2014) 6(8):a018614. doi:10.1101/cshperspect.a018614

62. Ouyang J, Zhu X, Chen Y, Wei H, Chen Q, Chi X, et al. NRAV, a long noncoding RNA, modulates antiviral responses through suppression of interferonstimulated gene transcription. Cell Host Microbe (2014) 16(5):616-26. doi:10.1016/j.chom.2014.10.001

63. Everitt AR, Clare S, Pertel T, John SP, Wash RS, Smith SE, et al. IFITM3 restricts the morbidity and mortality associated with influenza. Nature (2012) 484(7395):519-23. doi:10.1038/nature10921

64. Fensterl V, Wetzel JL, Ramachandran S, Ogino T, Stohlman SA, Bergmann CC, et al. Interferon-induced Ifit2/ISG54 protects mice from lethal VSV neuropathogenesis. PLoS Pathog (2012) 8(5):e1002712. doi:10.1371/journal.ppat. 1002712
65. Liu XY, Chen W, Wei B, Shan YF, Wang C. IFN-induced TPR protein IFIT3 potentiates antiviral signaling by bridging MAVS and TBK1. JImmunol (2011) 187(5):2559-68. doi:10.4049/jimmunol.1100963

66. Manz B, Dornfeld D, Gotz V, Zell R, Zimmermann P, Haller O, et al. Pandemic influenza A viruses escape from restriction by human MxA through adaptive mutations in the nucleoprotein. PLoS Pathog (2013) 9(3):e1003279. doi:10.1371/journal.ppat.1003279

67. Huang Z, Luo Q, Yang F, Qing C, Ye J, Deng Y, et al. Identification of differentially expressed long non-coding RNAs in polarized macrophages. Sci Rep (2016) 6:19705-14. doi:10.1038/srep19705

68. Nishitsuji H, Ujino S, Yoshio S, Sugiyama M, Mizokami M, Kanto T, et al. Long noncoding RNA\#32 contributes to antiviral responses by controlling interferon-stimulated gene expression. Proc Natl Acad Sci U S A (2016) 113(37):10388-93. doi:10.1073/pnas.1525022113

69. Pang KC, Dinger ME, Mercer TR, Malquori L, Grimmond SM, Chen W, et al. Genome-wide identification of long noncoding RNAs in CD8+ T cells. J Immunol (2009) 182(12):7738-48. doi:10.4049/jimmunol.0900603

70. Hu G, Tang Q, Sharma S, Yu F, Escobar TM, Muljo SA, et al. Expression and regulation of intergenic long noncoding RNAs during $\mathrm{T}$ cell development and differentiation. Nat Immunol (2013) 14(11):1190-8. doi:10.1038/ni.2712

71. Mourtada-Maarabouni M, Hedge VL, Kirkham L, Farzaneh F, Williams GT. Growth arrest in human T-cells is controlled by the non-coding RNA growth-arrest-specific transcript 5 (GAS5). J Cell Sci (2008) 121(7):939-46. doi: $10.1242 /$ jcs. 024646

72. Gomez JA, Wapinski OL, Yang YW, Bureau JF, Gopinath S, Monack DM, et al. The NeST long ncRNA controls microbial susceptibility and epigenetic activation of the interferon-gamma locus. Cell (2013) 152(4):743-54. doi:10.1016/j.cell.2013.01.015

73. Collier SP, Collins PL, Williams CL, Boothby MR, Aune TM. Cutting edge: influence of Tmevpg1, a long intergenic noncoding RNA, on the expression of ifng by Th1 cells. J Immunol (2012) 189(5):2084-8. doi:10.4049/ jimmunol.1200774

74. Collier SP, Henderson MA, Tossberg JT, Aune TM. Regulation of the Th1 genomic locus from ifng through Tmevpg1 by T-bet. JImmunol (2014) 193(8):3959-65. doi:10.4049/jimmunol.1401099

75. Vigneau S, Rohrlich PS, Brahic M, Bureau JF. Tmevpgl, a candidate gene for the control of Theiler's virus persistence, could be implicated in the regulation of gamma interferon. J Virol (2003) 77(10):5632-8. doi:10.1128/ JVI.77.10.5632-5638.2003

76. Willingham AT, Orth AP, Batalov S, Peters EC, Wen BG, Aza-Blanc P, et al. A strategy for probing the function of noncoding RNAs finds a repressor of NFAT. Science (2005) 309(5740):1570-3. doi:10.1126/science.1115901

77. Sharma S, Findlay GM, Bandukwala HS, Oberdoerffer S, Baust B, Li Z, et al. Dephosphorylation of the nuclear factor of activated T cells (NFAT) transcription factor is regulated by an RNA-protein scaffold complex. Proc Natl Acad Sci U S A (2011) 108(28):11381-6. doi:10.1073/pnas.1019711108

78. Imam H, Bano AS, Patel P, Holla P, Jameel S. The IncRNA NRON modulates HIV-1 replication in a NFAT-dependent manner and is differentially regulated by early and late viral proteins. Sci Rep (2015) 5:8639. doi:10.1038/srep08639

79. Aune TM, Spurlock CF. Long non-coding RNAs in innate and adaptive immunity. Virus Res (2016) 212:146-60. doi:10.1016/j.virusres.2015.07.003

80. Wang $\mathrm{P}, \mathrm{Xu}$ J, Wang Y, Cao X. An interferon-independent lncRNA promotes viral replication by modulating cellular metabolism. Science (2017). doi:10.1126/science.aao0409

81. Marx JL. "Viroids": a new kind of pathogen? Science (1972) 178(4062):734. doi:10.1126/science.178.4062.734

82. Mathews MB. Genes for VA-RNA in adenovirus 2. Cell (1975) 6(2):223-9. doi:10.1016/0092-8674(75)90013-6

83. Rossetto CC, Tarrant-Elorza M, Verma S, Purushothaman P, Pari GS. Regulation of viral and cellular gene expression by Kaposi's sarcoma-associated herpesvirus polyadenylated nuclear RNA. J Virol (2013) 87(10):5540-53. doi:10.1128/JVI.03111-12

84. Ahyi AN, Chang HC, Dent AL, Nutt SL, Kaplan MH, et al. IFN regulatory factor 4 regulates the expression of a subset of Th2 cytokines. J Immunol (2009) 183(3):1598-1596. doi:10.4049/jimmunol.0803302

85. Rossetto CC, Pari GS. Kaposi's sarcoma-associated herpesvirus noncoding polyadenylated nuclear RNA interacts with virus- and host cell-encoded proteins and suppresses expression of genes involved in immune modulation. J Virol (2011) 85(24):13290-7. doi:10.1128/JVI.05886-11 
86. Rossetto CC, Pari GS. KSHV PAN RNA associates with demethylases UTX and JMJD3 to activate lytic replication through a physical interaction with the virus genome. PLoS Pathog (2012) 8(5):e1002680. doi:10.1371/journal. ppat. 1002680

87. Borah S, Darricarrere N, Darnell A, Myoung J, Steitz JA. A viral nuclear noncoding RNA binds re-localized poly(A) binding protein and is required for late KSHV gene expression. PLoS Pathog (2011) 7(10):e1002300. doi:10.1371/journal.ppat.1002300

88. Gatherer D, Seirafian S, Cunningham C, Holton M, Dargan DJ, Baluchova K, et al. High-resolution human cytomegalovirus transcriptome. Proc Natl Acad Sci U S A (2011) 108(49):19755-60. doi:10.1073/pnas.1115861108

89. Poole E, Kuan WL, Barker R, Sinclair J. The human cytomegalovirus noncoding Beta2.7 RNA as a novel therapeutic for Parkinson's disease translational research with no translation. Virus Res (2016) 212:64-9. doi:10.1016/j.virusres.2015.05.007

90. Stern-Ginossar N, Weisburd B, Michalski A, Le VT, Hein MY, Huang SX, et al. Decoding human cytomegalovirus. Science (2012) 338(6110):1088-93. doi:10.1126/science. 1227919

91. Bergamini G, Reschke M, Battista MC, Boccuni MC, Campanini F, Ripalti A, et al. The major open reading frame of the Beta2.7 transcript of human cytomegalovirus: in vitro expression of a protein posttranscriptionally regulated by the 5' region. J Virol (1998) 72(10):8425-9.

92. Reeves MB, Davies AA, McSharry BP, Wilkinson GW, Sinclair JH. Complex I binding by a virally encoded RNA regulates mitochondria-induced cell death. Science (2007) 316(5829):1345-8. doi:10.1126/science.1142984

93. Lee JE, Lee JY, Trembly J, Wilusz J, Tian B, Wilusz CJ. The PARN deadenylase targets a discrete set of mRNAs for decay and regulates cell motility in mouse myoblasts. PLoS Genet (2012) 8(8):e1002901. doi:10.1371/journal. pgen.1002901
94. Moon SL, Anderson JR, Kumagai Y, Wilusz CJ, Akira S, Khromykh AA, et al A noncoding RNA produced by arthropod-borne flaviviruses inhibits the cellular exoribonuclease XRN1 and alters host mRNA stability. RNA (2012) 18(11):2029-40. doi:10.1261/rna.034330.112

95. Moon SL, Blackinton JG, Anderson JR, Dozier MK, Dodd BJ, Keene JD, et al. XRN1 stalling in the 5' UTR of hepatitis $\mathrm{C}$ virus and bovine viral diarrhea virus is associated with dysregulated host mRNA stability. PLoS Pathog (2015) 11(3):e1004708. doi:10.1371/journal.ppat.1004708

96. Charley PA, Wilusz J. Standing your ground to exoribonucleases: function of flavivirus long non-coding RNAs. Virus Res (2016) 212:70-7. doi:10.1016/ j.virusres.2015.09.009

97. Memczak S, Jens M, Elefsinioti A, Torti F, Krueger J, Rybak A, et al. Circular RNAs are a large class of animal RNAs with regulatory potency. Nature (2013) 495(7441):333-8. doi:10.1038/nature11928

98. Tay Y, Rinn J, Pandolfi PP. The multilayered complexity of ceRNA crosstalk and competition. Nature (2014) 505(7483):344-52. doi:10.1038/ nature 12986

Conflict of Interest Statement: The authors declare that the research was conducted in the absence of any commercial or financial relationships that could be construed as a potential conflict of interest.

Copyright (C) 2017 Meng, Luo, Anwar, Sun, Gao, Zhang, Munir and Qiu. This is an open-access article distributed under the terms of the Creative Commons Attribution License (CC BY). The use, distribution or reproduction in other forums is permitted, provided the original author(s) or licensor are credited and that the original publication in this journal is cited, in accordance with accepted academic practice. No use, distribution or reproduction is permitted which does not comply with these terms. 